Gynecologic and

Obstetric Investigation
Gynecol Obstet Invest

DOI: $10.1159 / 000320742$
Received: July 7, 2008

Accepted after revision: April 21, 2010

Published online: December 9, 2010

\title{
Hormonal Contraceptives and the Length of Their Use Are Not Independent Risk Factors for High-Risk HPV Infections or High-Grade CIN
}

\author{
Adhemar Longatto-Filho ${ }^{a, b}$ Luciano Serpa Hammes ${ }^{c}$ Luis Otavio Sarian ${ }^{d}$ \\ Cecília Roteli-Martins $^{e}$ Sophie F.M. Derchain ${ }^{d}$ Mojca Eržen ${ }^{f}$ \\ Margherita Brancag Sílvio Tatti ${ }^{\mathrm{h}}$ Paulo Naud ${ }^{\mathrm{c}}$ Jean Carlos de Matos ${ }^{\mathrm{c}}$ \\ Renata Gontijo $^{d}$ Marina Y.S. Maeda ${ }^{b}$ Temístocles Lima ${ }^{\mathrm{e}}$ Silvano Costa ${ }^{\mathrm{i}}$ \\ Stina Syrjänen ${ }^{j} \quad$ Kari Syrjänen ${ }^{k}$ \\ aLife and Health Sciences Research Institute, School of Health Sciences, University of Minho, Braga, Portugal; \\ ${ }^{b}$ Laboratory of Medical Investigation (LIM) 14, Faculty of Medicine University São Paulo, São Paulo, \\ 'Hospital de Clinicas de Porto Alegre, Porto Alegre, ${ }^{d}$ Universidade Estadual de Campinas, and \\ eHospital Leonor Mendes de Barros (HLMB), São Paulo, Brazil; fSIZE Diagnostic Center, Ljubljana, Slovenia; \\ gUnit of Cytopathology, National Centre of Epidemiology, Surveillance and Promotion of Health, National Institute \\ of Health (ISS), Rome, Italy; ${ }^{\text {h}}$ First Chair Gynecology Hospital de Clinicas, Buenos Aires, Argentina; ${ }^{\text {iDepartment of }}$ \\ Obstetrics and Gynecology, S. Orsola-Malpighi Hospital, Bologna, Italy; jDepartment of Oral Pathology, University \\ of Turku, and kDepartment of Oncology and Radiotherapy, Turku University Hospital, Turku, Finland
}

\section{Key Words}

Hormonal contraceptives • Cervical intraepithelial lesions •

High-risk human papillomavirus • Cohort study

\begin{abstract}
Aims: To evaluate the role of hormonal contraceptives as a risk factor of high-risk human papillomavirus (HR-HPV), cervical intraepithelial lesions (CIN) and cervical cancer in our multi-center population-based LAMS (Latin American Screening) study. Methods: A cohort study with $>12,000$ women from Brazil and Argentina using logistic regression to analyze the covariates of hormonal contraception (HOC - oral, injections, patches, implants, vaginal ring and progesterone intrauterine system) use followed by multivariate modeling for predictors of HR-HPV and CIN2+. Results:
\end{abstract}

HR-HPV infection was a consistent risk factor of high-grade $\mathrm{CIN}$ in all three groups of women. The length of $\mathrm{HOC}$ use was not significantly related to high-grade squamous intraepithelial lesions (HSIL)+Pap $(p=0.069), L S I L+\operatorname{Pap}(p=0.781)$ or ASCUS+ $(p=0.231)$. The same was true with the length of HOC use and histology CIN3+ $(p=0.115)$ and CIN2+ $(p=$ 0.515). Frequently, HOC users have previously shown more HPV-related lesions, as well as lower HPV prevalence if they were current smokers. But HOC use and time of usage were not independent risk factors of either HR-HPV infection or high-grade CIN using multiple logistic regressions. Conclusions: No evidence was found for an association between the use of HOC with an increased risk for HR-HPV infection or high-grade CIN in this cohort.

Copyright $\odot 2010$ S. Karger AG, Basel

Adhemar Longatto-Filho, M.Sc., PhD, PMIAC

Life and Health Sciences Research Institute

School of Health Sciences, University of Minho

PT-4710-057 Braga (Portugal)

Tel. +351 25360 4827, Fax +351 25360 4847, E-Mail longatto@ ecsaude.uminho.pt 


\section{Introduction}

The implicated increased risk of cervical cancer (CC) associated with the use of oral contraceptives or other types of hormonal contraception (HOC) is not consistent across the reported studies. Many studies report only weak association of oral contraceptive with high-grade squamous intraepithelial lesions (HSIL) and/or highgrade cervical intraepithelial lesions (CIN) [1]. Importantly, these reports are highly contradictory; there are substantially more studies failing to find an association than those reporting increased risk [2]. These apparently contentious results may reflect an improved cytological surveillance of oral contraceptive users in developed countries. This is important because the long-term use of oral contraceptives is increasingly common, predisposing these women to potential interactions with high-risk human papillomavirus (HR-HPV) infections [1]. Indeed, long-term oral contraceptive use may have an important impact in populations that are highly exposed to HPV, and these women may need closer surveillance for cytological abnormalities and HPV infections than women in the general population [1-3].

Recent data on the association between hormonal contraceptives and CC have shown a linear dose-response relationship; this effect tends to disappear within a time interval of 5-10 years after oral contraceptive cessation [3]. According to a recent meta-analysis comparing never-users of oral contraceptives with continuous current users, the relative risks of CC increased with increasing duration of use: for periods under 5 years, 5-9 years, and 10 or more years, respectively, the summary relative risks were 1.1 (95\% CI 1.1-1.2), $1.6(1.4-1.7)$ and $2.2(1.9-2.4)$ for all women, and $0.9(0.7-1.2), 1.3(1.0-1.9)$ and 2.5 (1.63.9) for women testing HPV-positive [2]. The results were generally similar for invasive and in situ cervical cancers, squamous cells and adenocarcinoma. Nevertheless, the limitations of these data are recognized and ascribed to variable study designs and heterogeneity between the reported results [2].

Because of this inconsistency, the public health implications of these findings depend largely on the duration of the persistent risk after cessation of the oral contraceptive usage [2]. Among British women, the use of oral contraceptives grew rapidly during the 1960s and by the 1980s, the incidence of CC among British women younger than 35 years increased by almost $25 \%$. The analyses of the odds ratios for CC have suggested that about $23 \%$ of these cases could be attributable to the use of oral contraceptives [4]. However, because sexual behavior is dif- ferent among oral contraceptive users, non-oral contraceptive users and non-users of contraception, the assessment of cancer risk must be judiciously evaluated. Indeed, several risk factors predispose women to HR-HPV and high-grade CIN, and determine the outcome of their cervical disease/HR-HPV infection. As demonstrated recently in a multicenter NIS cohort, the use of oral contraceptives was not an independent risk factor for any of these intermediate endpoint markers of cervical carcinogenesis [5]. Currently, long-term persistent HR-HPV infection is implicated as the most confident independent predictor of high-grade CIN in many studies [6].

The number of sexual partners, early age at first intercourse, parity and duration of oral contraceptive were found to be significantly associated with an increased risk of CC in a recent study conducted in Brazil [7], but after adjustment, HOC did not remain as an independent risk factor. In another cohort study on low-income women from São Paulo, women who had taken oral contraceptives were more likely to have oncogenic HPV infections than never-users. Actually, oral contraceptive use was strongly and exclusively associated with oncogenic and HPV16 infections [8]. These data are important because of the high incidence of HPV infections and high annual rates of mortality consequent to CC in South America as a whole. Tragically, for several regions, including Latin America, the Caribbean and Eastern Europe, cancer of the cervix still makes a greater contribution to lost years of life than diseases such as tuberculosis, maternal conditions or AIDS [9].

In the ongoing multicenter, population-based LAMS (Latin American Screening) Study testing optional screening tools in a cohort of $>12,000$ women in Brazil and Argentina, we analyzed hormonal contraception use as the potential risk factor for HR-HPV, CIN and CC. First, logistic regression was used to assess the covariates associated with hormonal contraception use by comparing three groups (including hormonal contraception users, non-hormonal contraception users and non-users of contraception), followed by analysis of the predictors of HR-HPV and CIN2+ in univariate and multiple logistic regression.

\section{Materials and Methods}

General Study Design

The ongoing LAMS study is a European Union (EU)-funded multicenter screening trial targeting the female populations at different risk for CC in two Latin American countries, Brazil and Argentina [10]. In the LAMS study cohort $(n=12,114)$, eight dif- 
ferent diagnostic tests are compared as optional screening tools in a low-resource setting: conventional Pap smear, liquid-based cytology (LBC), visual inspection with acetic acid and with iodine solution, cervicography, screening colposcopy, and HR-HPV testing (self-sampling and collected by physician) [11-15].

The LAMS study is a combination of a population-based, cross-sectional and a prospective cohort study of women enrolled in regions with different (low, intermediate, high) incidence of CC in these two countries. Consecutive series of women at their first visit at four clinics (three in Brazil and one in Argentina) were screened for cervical HR-HPV infections and CIN, using different tests as described before [10]. Women testing positive with any of these techniques were examined by colposcopy at the next visit. Additionally, a 5\% random sample of Pap-negative women were recalled for a new Pap test at 12 months, as were $20 \%$ of those testing HCII negative, to assess the rates of incident Pap smear abnormalities and HR-HPV infections $[11,13]$. The women with biopsyconfirmed low-grade CIN, abnormal Pap or those testing HR$\mathrm{HPV}+$ comprised the cohort prospectively followed up for a minimum of 24 months, at 6-month intervals. All high-grade lesions were promptly treated and followed up for the same period. Altogether, 1,011 women were followed up for $38.77 \pm 4.85$ months.

\section{Patients}

The four clinics examined a total of 12,114 women between February 2002 and June 2003, comprising the LAMS study cohort [10]. The mean age of the women at enrolment was 37.9 years (range: 14-67; median: 37.7).

At the first visit, patients were asked to fill in a structured questionnaire recording epidemiological characteristics and risk factors of CC. This questionnaire included records on the modes of contraception used by these women, including the total time of hormonal contraception usage. For the present analysis, patients were divided into three groups: (a) users of hormonal contraception (HOC - oral, injections, patches, implants, vaginal ring and progesterone intrauterine system), (b) women with no contraception, and (c) those using other modes of contraception (condom, intrauterine device, tubal sterilization, diaphragm, male sterilization). Furthermore, for statistical analysis purposes, women were also divided in two groups: (a) users of HOC and (b) women with no hormonal contraception.

\section{Pap Test Evaluation}

Cervical cytology was tested in three modes: conventional and two different LBC techniques [11]. Conventional Pap smear was taken by all centers, while LBC was tested in one clinic (Leonor Mendes de Barros Hospital) only. Interpretation of the smears follows the Bethesda 2001 system [16]. In the current analysis, all cytology results (conventional and LBC) were considered.

\section{HPV Testing}

HPV testing was done by Hybrid Capture 2 (HCII) assay, using cervical swabs (collected by a physician) and/or self-sampling devices (tampons), as described previously $[13,14]$. HCII assay was performed using the automated HCII test system according to the manufacturer's protocol. The samples were analyzed only for the high-risk HPV types 16, 18, 31, 33, 35, 39, 45, 51, 52, 56, 58, 59 and 68. The usual limit of $1 \mathrm{pg} / \mathrm{ml}$ of HPV16 DNA was used as the positive control (CO). Samples were classified as HR-HPV-posi- tive, if the relative light unit (RLU) reading of the luminometer was equal to or greater than the mean of CO values, i.e. RLU/CO $\geq 1.0 \mathrm{pg} / \mathrm{ml}$ was the cutoff for test positivity [13]. In this analysis, only the samples collected by the physicians were included.

\section{Cervical Biopsies}

Directed punch biopsies (and cone biopsies) were fixed in 10\% formalin, and paraffin-embedded. The 5 - $\mu \mathrm{m}$-thick sections were routinely stained in hematoxylin-eosin $(\mathrm{HE})$, examined among the daily routine in the pathology departments of the four clinics, and diagnosed using the commonly agreed CIN nomenclature $[10,13]$. CIN1 was considered low-grade CIN, whereas CIN2 and CIN3 were classified as high-grade CIN.

\section{Statistical Analysis}

Comparison of epidemiological variables across the three groups of contraception usage was performed with a $\chi^{2}$ test or Fisher's exact test for categorical variables and with the KruskalWallis test for continuous variables, which in our analysis presented non-normal distribution. Risk associates for abnormal cytology (HSIL/LSIL cutoffs), HR-HPV and CIN lesions were first calculated in univariate logistic regression, with a crude odds ratio (OR) and confidence intervals (95\% CI). All significant risk factors were entered in a multiple logistic regression (together with contraception variables), and the adjusted ORs (95\% CI) were calculated for two separate outcome variables: HR-HPV infections and CIN2+. In all tests, $\mathrm{p}<0.05$ was regarded as being statistically significant. No correction for multiple testing was performed. In a previous analysis of our cohort, we identified that population characteristics, risk factors and cervical lesions incidence was very similar among the four clinics, so we did not perform stratified analysis for each clinic.

Data were stored and analyzed using the SPSS statistical software (version 12.0, SPSS Inc., Chicago, Ill., USA).

\section{Results}

From the whole cohort, $98.73 \%$ of the patients completed the screening phase of the project and have available data of Pap smear. 97.88\% of the women have available results from Hybrid Capture tests.

Initially we analyzed the main characteristics of HOC users and non-users to show that they have different key epidemiological attributes, representing different subgroups (table 1). Several of these characteristics were significantly associated with the mode of contraception. Most strikingly, users of HOC were younger (mean age $34.65 \pm 10.59$ years) than women with no contraception $(42.50 \pm 11.83)$ and those using other contraception $(37.75 \pm 10.52)$. HOC users were less likely to be single, had the highest prevalence of HR-HPV, and had fewer progeny and abortions as compared to the two other groups. Another remarkable feature of HOC users was their more frequent history of HPV-related lesions, as 
Table 1. Key epidemiological characteristics related to the modality of contraception

\begin{tabular}{|c|c|c|c|c|}
\hline Characteristic & $\begin{array}{l}\text { Users of hormonal } \\
\text { contraception } \\
(\mathrm{n}=3,617)\end{array}$ & $\begin{array}{l}\text { Women with no } \\
\text { contraception } \\
(\mathrm{n}=2,637)\end{array}$ & $\begin{array}{l}\text { Users of other } \\
\text { contraception } \\
(n=5,830)\end{array}$ & $\begin{array}{l}\text { Signifi- } \\
\text { cance } \\
\text { p value* }\end{array}$ \\
\hline Age & $33.23(25.85 ; 42.31)$ & $44.50(32.74 ; 52.44)$ & $38.20(29.27 ; 45.81)$ & $<0.0001$ \\
\hline Years of education & $8.00(6.00 ; 11.00)$ & $8.00(5.00 ; 11.00)$ & $9.00(5.00 ; 12.00)$ & $<0.0001$ \\
\hline Marital status - single & $938 / 3,610(26.0 \%)$ & $1,036 / 2,636(39.3 \%)$ & $1,837 / 5,824(31.5 \%)$ & $<0.0001$ \\
\hline HR-HPV positive & $281 / 1,423(19.7 \%)$ & $139 / 875(15.9 \%)$ & $335 / 2,106(15.9 \%)$ & 0.006 \\
\hline HPV index & $0.35(0.25 ; 0.68)$ & $0.35(0.25 ; 0.57)$ & $0.34(0.25 ; 0.58)$ & 0.256 \\
\hline \multicolumn{5}{|l|}{ Pap smear } \\
\hline HSIL or worse & $50 / 3,613(1.4 \%)$ & $33 / 2,635(1.3 \%)$ & $66 / 5,825(1.1 \%)$ & 0.560 \\
\hline LSIL or worse & $107 / 3,613(3.0 \%)$ & $65 / 2,635(2.5 \%)$ & $132 / 5,825(2.3 \%)$ & 0.282 \\
\hline ASCUS or worse & $207 / 3,613(5.7 \%)$ & $138 / 2,635(5.2 \%)$ & $290 / 5,825(5.0 \%)$ & 0.283 \\
\hline \multicolumn{5}{|l|}{ Final screening diagnosis } \\
\hline CIN3 or cancer & $33 / 3,568(0.9 \%)$ & $29 / 2,605(1.1 \%)$ & $56 / 5,768(1.0 \%)$ & 0.748 \\
\hline CIN2 or worse & $54 / 3,568(1.5 \%)$ & $35 / 2,605(1.3 \%)$ & $86 / 5,768(1.5 \%)$ & 0.839 \\
\hline Any lesion & $159 / 3,568(4.5 \%)$ & $89 / 2,605(3.4 \%)$ & $231 / 5,768(4.0 \%)$ & 0.121 \\
\hline Ever been pregnant & $2,859 / 3,616(79.1 \%)$ & $2,080 / 2,637(78.9 \%)$ & $4,772 / 5,829(81.9 \%)$ & 0.0003 \\
\hline Number of deliveries & $1.00(0.00 ; 2.00)$ & $1.00(0.00 ; 3.00)$ & $1.00(0.00 ; 2.00)$ & $<0.0001$ \\
\hline Ever had abortions & $1,035 / 3,616(28.6 \%)$ & $963 / 2,637(36.5 \%)$ & $1,897 / 5,829(32.5 \%)$ & $<0.0001$ \\
\hline Number of abortions & $0.00(0.00 ; 1.00)$ & $0.00(0.00 ; 1.00)$ & $0.00(0.00 ; 1.00)$ & $<0.0001$ \\
\hline Age at first sexual intercourse & $18.15 \pm 3.58$ & $19.11 \pm 4.73$ & $18.45 \pm 3.72$ & $<0.0001$ \\
\hline Sexually active $e^{* *}$ & $3,355 / 3,615(92.8 \%)$ & $2,098 / 2,637(79.6 \%)$ & $5,359 / 5,828(92.0 \%)$ & $<0.0001$ \\
\hline Currently, only one sex partner & $3,192 / 3,615(88.3 \%)$ & $2,029 / 2,637(76.9 \%)$ & $5,057 / 5,828(86.8 \%)$ & $<0.0001$ \\
\hline Partners during previous 12 months, $\mathrm{n}$ & $1.00(1.00 ; 1.00)$ & $1.00(1.00 ; 1.00)$ & $1.00(1.00 ; 1.00)$ & $<0.0001$ \\
\hline Partners since the first intercourse, $\mathrm{n}$ & $2.00(1.00 ; 3.00)$ & $2.00(1.00 ; 3.00)$ & $2.00(1.00 ; 3.00)$ & 0.080 \\
\hline Ever had STD & $321 / 3,615(8.9 \%)$ & $166 / 2,636(6.3 \%)$ & $440 / 525(7.7 \%)$ & 0.001 \\
\hline Partner ever had STD & $335 / 3,615(9.3 \%)$ & $165 / 2,635(6.3 \%)$ & $463 / 5,828(7.9 \%)$ & $<0.0001$ \\
\hline Ever taken Pap smear & $370 / 3,617(10.2 \%)$ & $272 / 2,636(10.3 \%)$ & $610 / 5,828(10.5 \%)$ & 0.931 \\
\hline Lifetime Pap smears, $\mathrm{n}$ & $4.00(2.00 ; 10.00)$ & $5.00(3.00 ; 10.00)$ & $5.00(3.00 ; 10.00)$ & $<0.0001$ \\
\hline Time since the last Pap test, months & $15.00(12.00 ; 24.00)$ & $15.00(12.00 ; 24.00)$ & $14.00(12.00 ; 24.00)$ & 0.004 \\
\hline History of skin or genital warts & $99 / 3,616(2.7 \%)$ & $33 / 2,634(1.3 \%)$ & $118 / 5,826(2.0 \%)$ & 0.0002 \\
\hline History of previous CIN & $66 / 3,616(1.8 \%)$ & $17 / 2,635(0.6 \%)$ & $79 / 5,828(1.4 \%)$ & 0.002 \\
\hline Ever been smoker & $1,309 / 3,613(36.2 \%)$ & $994 / 2,634(37.7 \%)$ & $2,274 / 5,829(39.0 \%)$ & 0.025 \\
\hline Current smoker & $745 / 3,613(20.6 \%)$ & $588 / 2,634(22.3 \%)$ & $1,373 / 5,829(23.6 \%)$ & 0.003 \\
\hline If current smoker, for how long, years & $12.00(6.00 ; 20.00)$ & $20.00(10.00 ; 28.75)$ & $15.00(7.00 ; 23.00)$ & $<0.0001$ \\
\hline Smoked in the past & $564 / 3,613(15.6 \%)$ & $406 / 2,634(15.4 \%)$ & $901 / 5,829(15.5 \%)$ & 0.972 \\
\hline If smoked in the past, for how long, years & $6.00(2.00 ; 13.00)$ & $12.00(6.00 ; 20.00)$ & $12.00(6.00 ; 20.00)$ & $<0.0001$ \\
\hline Time since stopped smoking, months & $5.00(2.00 ; 10.00)$ & $6.00(3.00 ; 15.00)$ & $5.00(2.00 ; 11.50)$ & $<0.0001$ \\
\hline
\end{tabular}

Values presented in median (25th; 75 th percentile) when not percentage. ${ }^{*}$ Kruskal-Wallis test for values presented in median and $\chi^{2}$ test for values presented in percentage. ${ }^{* *}$ Last sexual intercourse $<12$ months.

well as lower HPV prevalence if they were current smokers.

Then, we analyzed if risk factors for HPV infection and CIN were differently distributed among HOC users and non-users (tables 2 and 3). Specifically, table 2 summarizes the key epidemiological risk factors of highgrade CIN, stratified according to the mode of contraception. Positive HR-HPV status and abnormal Pap were significantly related to CIN in all three groups, whereas being single, age at first sexual intercourse, $>5$ lifetime sexual partners, number of deliveries, onset of sexual activity and ever being a smoker were not universally related to CIN in the three groups of women. The key epidemiological risk factors of HR-HPV infection are shown in table 3. Age and number of sexual partners were associated with HR-HPV infection in all three groups. Similar data were also calculated for predictors of HSIL Pap (data not shown). Then, only HR-HPV+ status was a consistent risk factor for HSIL in all three groups of women. 
Table 2. Predictors of high-grade CIN in women with different modalities of contraception

\begin{tabular}{|c|c|c|c|c|c|c|}
\hline \multirow[t]{2}{*}{ Covariate } & \multicolumn{2}{|c|}{$\begin{array}{l}\text { Users of hormonal } \\
\text { contraception }\end{array}$} & \multicolumn{2}{|l|}{$\begin{array}{l}\text { Women with no } \\
\text { contraception }\end{array}$} & \multicolumn{2}{|l|}{$\begin{array}{l}\text { Users of other } \\
\text { contraception }\end{array}$} \\
\hline & OR $(95 \% \mathrm{CI})$ & $\mathrm{p}$ & OR (95\% CI) & $\mathrm{p}$ & OR $(95 \% \mathrm{CI})$ & $\mathrm{p}$ \\
\hline Age $<35$ years & $\begin{array}{l}1.23 \\
(0.71-2.19)\end{array}$ & 0.465 & $\begin{array}{l}0.86 \\
(0.40-1.83)\end{array}$ & 0.0688 & $\begin{array}{l}1.56 \\
(1.02-2.40)\end{array}$ & 0.037 \\
\hline Marital status - single & $\begin{array}{l}0.91 \\
(0.49-1.71)\end{array}$ & 0.781 & $\begin{array}{l}1.47 \\
(0.75-2.87)\end{array}$ & 0.251 & $\begin{array}{l}2.20 \\
(1.44-3.37)\end{array}$ & $<0.0001$ \\
\hline HCII test+ & $\begin{array}{l}19.24 \\
(6.42-57.68)\end{array}$ & $<0.0001$ & $\begin{array}{l}55.25 \\
(6.97-442.29)\end{array}$ & $<0.0001$ & $\begin{array}{l}20.30 \\
(9.53-43.21)\end{array}$ & $<0.0001$ \\
\hline HSIL Pap or worse & $\begin{array}{l}181.31 \\
(90.47-363.34)\end{array}$ & $<0.0001^{*}$ & $\begin{array}{l}620.61 \\
(235.66-1,634.35)\end{array}$ & $<0.0001^{*}$ & $\begin{array}{l}196.62 \\
(110.33-350.42)\end{array}$ & $<0.0001^{*}$ \\
\hline LSIL Pap or worse & $\begin{array}{l}79.97 \\
(43.75-146.16)\end{array}$ & $<0.0001^{*}$ & $\begin{array}{l}197.69 \\
(86.67-450.92)\end{array}$ & $<0.0001^{*}$ & $\begin{array}{l}73.09 \\
(45.46-117.51)\end{array}$ & $<0.0001^{*}$ \\
\hline ASCUS Pap or worse & $\begin{array}{l}53.42 \\
(28.78-99.16)\end{array}$ & $<0.0001^{*}$ & $\begin{array}{l}204.06 \\
(70.59-589.84)\end{array}$ & $<0.0001^{*}$ & $\begin{array}{l}48.99 \\
(30.71-78.16)\end{array}$ & $<0.0001^{*}$ \\
\hline $\begin{array}{l}\text { Age at first sexual intercourse } \\
\text { below mean** }\end{array}$ & $\begin{array}{l}2.69 \\
(1.31-5.51)\end{array}$ & 0.005 & $\begin{array}{l}1.83 \\
(0.89-3.74)\end{array}$ & 0.095 & $\begin{array}{l}1.55 \\
(0.97-2.46)\end{array}$ & 0.068 \\
\hline $\begin{array}{l}\text { Number of partners }>5 \text { since } \\
\text { first sexual intercourse }\end{array}$ & $\begin{array}{l}1.45 \\
(0.72-2.9)\end{array}$ & 0.292 & $\begin{array}{l}0.46 \\
(0.11-1.92)\end{array}$ & $0.423^{*}$ & $\begin{array}{l}2.72 \\
(1.69-4.35)\end{array}$ & $<0.0001$ \\
\hline Ever been pregnant & $\begin{array}{l}1.33 \\
(0.65-2.74)\end{array}$ & 0.434 & $\begin{array}{l}2.08 \\
(0.73-5.92)\end{array}$ & 0.160 & $\begin{array}{l}0.68 \\
(0.42-1.12)\end{array}$ & 0.129 \\
\hline Ever had an STD & $\begin{array}{l}1.81 \\
(0.85-3.88)\end{array}$ & $0.140^{*}$ & $\begin{array}{l}0.42 \\
(0.01-21.01)\end{array}$ & 0.585 & $\begin{array}{l}1.84 \\
(0.97-3.49)\end{array}$ & $0.093^{*}$ \\
\hline Partner ever had an STD & $\begin{array}{l}1.72 \\
(0.81-3.67)\end{array}$ & 0.158 & $\begin{array}{l}0.42 \\
(0.01-2.56)\end{array}$ & 0.166 & $\begin{array}{l}1.37 \\
(0.68-2.76)\end{array}$ & 0.369 \\
\hline Previous Pap taken - never had & $\begin{array}{l}1.55 \\
(0.73-3.32)\end{array}$ & 0.249 & $\begin{array}{l}1.48 \\
(0.56-3.85)\end{array}$ & 0.418 & $\begin{array}{l}1.25 \\
(0.66-2.38)\end{array}$ & 0.480 \\
\hline Ever been smoker & $\begin{array}{l}1.65 \\
(0.97-2.83)\end{array}$ & 0.064 & $\begin{array}{l}0.98 \\
(0.49-1.95)\end{array}$ & 0.945 & $\begin{array}{l}1.64 \\
(1.07-2.51)\end{array}$ & 0.021 \\
\hline
\end{tabular}

OR calculated for CIN2+ cutoff with univariate regression. * Fisher's exact test - all other p values were calculated by Pearson $\chi^{2}$. ** Mean age at first sexual intercourse $=18.51$ years.

We also performed a multiple logistic regression analysis to evaluate if use of HOC was a risk factor for HPV infection or high-grade CIN (table 4). Age below 35 years, Pap and histological abnormalities, never had a Pap smear, and marital status, including the number of lifetime sex partners were significant independent risk factors of HR-HPV. HR-HPV and abnormal Pap smear were significantly associated with high-grade CIN. Importantly, HOC use were not independent risk factors of either HR-HPV infection or high-grade CIN in this multiple logistic regression.

Hormonal Contraceptives and Cervical Cancer
We also analyzed the time of $\mathrm{HOC}$ use as related to HR-HPV infection, HSIL/LSIL and CIN outcomes (table 5). Interestingly, women testing positive for HRHPV reported shorter use of HOC than woman testing negative for HR-HPV and this finding was also identified when we considered only women younger than 35 years.

As this study has a follow-up phase, we analyzed if the use of HOC influenced the outcome (cure, persistence or progression) of HPV infection, abnormal Pap smear or CIN lesions (table 6). The baseline HPV/Pap smear status 
Table 3. Predictors of HR-HPV infection in women with different modalities of contraception

\begin{tabular}{|c|c|c|c|c|c|c|}
\hline \multirow[t]{2}{*}{ Covariate } & \multicolumn{2}{|c|}{ Users of hormonal contraception } & \multicolumn{2}{|c|}{ Women with no contraception } & \multicolumn{2}{|c|}{ Users of other contraception } \\
\hline & OR $(95 \% \mathrm{CI})$ & $\mathrm{p}$ & OR (95\% CI) & $\mathrm{p}$ & OR (95\% CI) & $\mathrm{p}$ \\
\hline Age $<35$ years & $1.97(1.49-2.60)$ & $<0.0001$ & $1.88(1.29-2.74)$ & 0.001 & $2.21(1.75-2.80)$ & $<0.0001$ \\
\hline Marital status - single & $1.81(1.37-2.39)$ & $<0.0001$ & $1.20(0.83-1.73)$ & 0.331 & $2.25(1.78-2.86)$ & $<0.0001$ \\
\hline HSIL Pap or worse & $21.47(6.17-74.70)$ & $<0.0001^{*}$ & $22.41(4.71-106.72)$ & $<0.0001^{*}$ & $21.19(9.12-49.25)$ & $<0.0001$ \\
\hline LSIL Pap or worse & $20.90(9.59-45.51)$ & $<0.0001$ & $9.77(4.19-22.82)$ & $<0.0001^{*}$ & $19.09(10.54-34.60)$ & $<0.0001$ \\
\hline ASCUS Pap or worse & $7.32(4.80-11.17)$ & $<0.0001$ & $7.52(4.28-13.19)$ & $<0.0001$ & $10.00(6.89-14.50)$ & $<0.0001$ \\
\hline Age at first sexual intercourse below mean** & $1.72(1.28-2.32)$ & $<0.0001$ & $1.32(0.91-1.91)$ & 0.140 & $1.80(1.39-2.33)$ & $<0.0001$ \\
\hline Partners $>5$ since first sexual intercourse, $n$ & $2.18(1.57-3.02)$ & $<0.0001$ & $1.88(1.18-3.01)$ & 0.008 & $2.02(1.52-2.70)$ & $<0.0001$ \\
\hline Ever been pregnant & $0.51(0.38-0.68)$ & $<0.0001$ & $0.67(0.44-1.02)$ & 0.060 & $0.50(0.38-0.66)$ & $<0.0001$ \\
\hline Ever had an STD & $0.99(0.64-1.53)$ & 0.954 & $0.73(0.34-1.56)$ & 0.412 & $1.18(0.82-1.69)$ & 0.419 \\
\hline Partner ever had an STD & $1.05(0.68-1.62)$ & 0.831 & $0.89(0.43-1.85)$ & 0.760 & $1.21(0.84-1.74)$ & 0.347 \\
\hline Previous Pap taken - never had & $1.70(1.14-2.54)$ & 0.009 & $1.49(0.85-2.59)$ & 0.160 & $1.67(1.17-2.38)$ & 0.006 \\
\hline Ever been smoker & $1.22(0.93-1.59)$ & 0.153 & $1.27(0.88-1.84)$ & 0.194 & $1.06(0.84-1.34)$ & 0.679 \\
\hline
\end{tabular}

OR calculated for high-risk HPV detected by Hybrid Capture II with univariate regression. * Fisher's exact test - all other p values were calculated by Pearson $\chi^{2} .{ }^{* *}$ Mean age at first sexual intercourse $=18.51$ years.

Table 4. Predictors of HR-HPV infections and high-grade CIN in multiple logistic regression analysis

\begin{tabular}{|c|c|c|c|c|}
\hline \multirow[t]{2}{*}{ Covariates } & \multicolumn{2}{|c|}{ Outcome: HR-HPV infection } & \multicolumn{2}{|c|}{ Outcome: high-grade CIN } \\
\hline & adjusted OR (95\% CI) & $\mathrm{p}$ & adjusted OR (95\% CI) & $\mathrm{p}$ \\
\hline Positive baseline RH-HPV test & & & $8.66(4.40-17.04)$ & $<0.0001$ \\
\hline Age $<35$ years & $1.68(1.39-2.04)$ & $<0.0001$ & $1.58(0.82-3.04)$ & 0.169 \\
\hline HSIL Pap & $3.16(1.23-8.12)$ & 0.017 & $53.28(10.90-259.77)$ & $<0.0001$ \\
\hline LSIL Pap & $11.42(6.62-19.68)$ & $<0.0001$ & $13.89(7.38-26.12)$ & $<0.0001$ \\
\hline High-grade CIN (CIN2 and above) & $8.63(4.45-16.74)$ & $<0.0001$ & & \\
\hline Other contraception & $0.94(0.74-1.19)$ & 0.609 & $1.18(0.52-2.69)$ & 0.684 \\
\hline Hormonal contraception* & $1.15(0.90-1.48)$ & 0.258 & $0.83(0.34-2.05)$ & 0.699 \\
\hline Ever been pregnant (yes/no) & $0.82(0.65-1.04)$ & 0.063 & $1.22(0.56-2.64)$ & 0.608 \\
\hline Deliveries, $\mathrm{n}$ & $0.99(0.93-1.05)$ & 0.548 & $0.99(0.93-1.05)$ & 0.548 \\
\hline Early onset of sexual activity ( $\leq 14$ years) & $0.91(0.69-1.19)$ & 0.509 & $1.13(0.57-2.23)$ & 0.720 \\
\hline No previous Pap & $1.37(1.04-1.80)$ & 0.023 & $2.34(1.03-5.29)$ & 0.040 \\
\hline Ever smoker & $1.16(0.97-1.38)$ & 0.451 & $1.01(0.67-1.51)$ & 0.963 \\
\hline Marital status (single) & $1.40(1.16-1.69)$ & $<0.0001$ & $1.53(0.81-2.89)$ & 0.184 \\
\hline $2-4$ lifetime partners & $1.78(1.45-2.19)$ & $<0.0001$ & $0.70(0.34-1.42)$ & 0.330 \\
\hline$>5$ partners & $2.51(1.93-3.27)$ & $<0.0001$ & $1.25(0.54-2.88)$ & 0.588 \\
\hline Partner with STD & $0.78(0.55-1.11)$ & 0.177 & $0.66(0.20-5.91)$ & 0.499 \\
\hline History of STD & $0.76(0.53-1.08)$ & 0.134 & $2.09(0.74-5.91)$ & 0.499 \\
\hline
\end{tabular}

* Additional subanalysis was performed with HOC time of usage (5-, 10- and 15-year cutoff) with no association to HR-HPV infection or high-grade CIN.

did not vary according to the modality of contraception. Outcomes of Pap smear abnormalities, HR-HPV infections and CIN during the follow-up were measured by different variables, but no correlation with the modality of contraception was observed.
The prospective follow-up of these women for over 24 months revealed that incident Pap abnormalities were equally frequent among women with baseline abnormal Pap, baseline HR-HPV+ test or a combination of both, irrespective of their mode of contraception (table 7). The 
Table 5. The relation of time of HOC use and HR-HPV infection, HSIL/LSIL and CIN outcomes

\begin{tabular}{lll}
\hline Outcome & $\begin{array}{l}\text { Years of HOC } \\
\text { usage (mean } \pm \text { SD) }\end{array}$ & $\begin{array}{l}p \\
\text { value }\end{array}$ \\
\hline HSIL & $9.6 \pm 6.4$ & 0.069 \\
Without HSIL & $8.3 \pm 6.9$ & \\
\hline LSIL & $7.9 \pm 6.3$ & 0.781 \\
Without LSIL & $8.3 \pm 6.9$ & \\
\hline CIN1+ & $6.8 \pm 5.7$ & 0,013 \\
Without CIN1+ & $8.4 \pm 6.9$ & 0.515 \\
\hline CIN2+ & $8.8 \pm 6.8$ & 0.115 \\
Without CIN2+ & $8.3 \pm 6.9$ & \\
\hline CIN3+ & $9.8 \pm 6.5$ & 0.0001 \\
Without CIN3+ & $8.3 \pm 6.9$ & \\
\hline HR-HPV+ & $6.4 \pm 5.7$ & 0.007 \\
HR-HPV- & $8.5 \pm 6.8$ & \\
\hline HR-HPV+ women $<35$ years & $4.4 \pm 3.4$ & \\
HR-HPV- women $<35$ years & $5.4 \pm 4.3$ &
\end{tabular}

No such difference related to HR-HPV status was observed among woman aged 35 years or more $(p=0.286)$. Setting the cutoff to 30 years, all these differences disappeared.

only exceptions were the group of baseline HR-HPV-/ Pap+ and HR-HPV+/Pap- women with no contraception, who had a hazard ratio (HR) for incident abnormal Pap similar to that of baseline HR-HPV-/Pap- women. Women with persistent HPV infections had a higher probability of acquiring Pap smear abnormalities during the follow-up, regardless of their contraception status. Women who acquired incident HR-HPV during the follow-up or had a fluctuating HR-HPV status were not at increased risk of Pap smear abnormalities, whereas women who cleared their baseline HR-HPV infection and were users of HOC or other contraceptive methods were at a higher risk of acquiring Pap abnormalities.

We also analyzed the appearance of CIN during the follow-up as related to the baseline status of the women. The following variables were associated with an increased risk of developing CIN (HR; 95\% CI): HR-HPV infection (4.17; 1.74-9.96) and LSIL Pap at baseline $(1.99 ; 1.42$ 2.80 ). On the other hand, a large number of variables were not related to appearance of CIN, including age $>35$ years, baseline HSIL Pap, ever been pregnant, number of deliveries, recent partner, early onset of sexual activity, current smoker and being single. The use of other modes of con- traception (not hormonal) was not protective against incident CIN (0.72; 0.29-1.76). Importantly, no evidence for association of HOC usage and disease progression for CIN was found (HR: 1.20 ; 95\% CI: 0.50-2.87).

\section{Discussion}

Re-analysis of the data from the International Collaboration of Epidemiological Studies of Cervical Cancer have recently confirmed that current and recent use of combined oral contraceptives is indeed associated with an increased risk of invasive CC [17]. According to these sizeable figures from 24 epidemiological studies, the relative risk in current users augments with increasing duration of oral contraceptive use. Use for 5 or more years (mean: 11.1 years) is associated with doubling of the risk. Relative risks were broadly similar among women likely not to have been screened and in women likely to have been screened, in analyses restricted to HR-HPV+ women, as well as for CIN3/carcinoma in situ [17].

In the present cohort of over 12,000 women, we failed to confirm any part of the results from this pivotal metaanalysis [17]. Our data unequivocally showed that hormonal contraceptive use (or length of use) is not an independent risk factor of high-grade CIN lesions. It is important to note that our study considered users of 'hormonal contraception' as oral, injections, patches, implants, vaginal ring and progesterone intrauterine system, while other studies analyzed only users of oral contraceptives. We decided to combine all types of hormonal contraception because we considered that all of them could have potential hormonal influence and taking them together would give a more robust cause-effect analysis.

Our data fully confirm the recently reported results from another screening trial (NIS - New Independent States of the former Soviet Union cohort) in a low-resource setting, demonstrating that oral contraceptive use was not an independent risk factor of any of the intermediate endpoint markers in cervical carcinogenesis [5]. Indeed, the possible association of HOC use and CC is made far more complex by the strong causal link of HR-HPV types to CC [18]. This is because HPV infections are closely related to the sexual behavior of women (and their partners), and these adopted sexual habits are in turn closely linked with individual women's preferences for contraception modes. Because of this fact, studies claiming a causal association between HOC and CC should be able to control for the confounding effect of both HRHPV and sexual habits [18]. 
Table 6. Baseline status and clinical outcome of cervical lesions and HR-HPV infections as related to the mode of contraception

\begin{tabular}{|c|c|c|c|c|}
\hline & $\begin{array}{l}\text { Hormonal } \\
\text { contraception, \% }\end{array}$ & $\begin{array}{l}\text { Other mode of } \\
\text { contraception, \% }\end{array}$ & $\begin{array}{l}\text { No } \\
\text { contraception, \% }\end{array}$ & $\mathrm{p}^{\#}$ \\
\hline \multicolumn{5}{|l|}{ Baseline status ${ }^{a}$} \\
\hline HR-HPV-/Pap- & $21.69(72 / 332)$ & $27.47(100 / 364)$ & $21.5(23 / 107)$ & 0.437 \\
\hline HR-HPV-/Pap+ & $13.25(44 / 332)$ & $13.46(49 / 364)$ & $14.02(15 / 107)$ & \\
\hline HR-HPV+/Pap- & $49.4(164 / 332)$ & $44.78(163 / 364)$ & $43.93(47 / 107)$ & \\
\hline HR-HPV+/Pap+ & $15.66(52 / 332)$ & $14.29(52 / 364)$ & $20.56(22 / 107)$ & \\
\hline \multicolumn{5}{|c|}{ Follow-up outcome of HR-HPV infection ${ }^{b}$} \\
\hline Always negative & $33.0(89 / 270)$ & $35.3(85 / 241)$ & $31.1(19 / 61)$ & 0.302 \\
\hline New infection & $2.2(6 / 270)$ & $4.1(10 / 241)$ & $4.9(3 / 61)$ & \\
\hline Persistence & $19.3(52 / 270)$ & $17.4(42 / 241)$ & $18.0(11 / 61)$ & \\
\hline Cleared & $40.4(109 / 270)$ & $41.9(101 / 241)$ & $44.3(27 / 61)$ & \\
\hline Fluctuation & $5.2(14 / 270)$ & $1.2(3 / 241)$ & $1.6(1 / 61)$ & \\
\hline \multicolumn{5}{|l|}{ Follow-up outcome of Pap smear ${ }^{c}$} \\
\hline Always negative & $54.9(218 / 397)$ & $55.2(253 / 458)$ & $50.7(76 / 150)$ & 0.343 \\
\hline New abnormal Pap & $14.6(58 / 397)$ & $12.4(57 / 458)$ & $10.7(16 / 150)$ & \\
\hline Persistent abnormal Pap & $4.8(19 / 397)$ & $3.1(14 / 458)$ & $4.00(6 / 150)$ & \\
\hline Cleared abnormal Pap & $22.7(90 / 397)$ & $25.5(117 / 458)$ & $32.7(49 / 150)$ & \\
\hline Fluctuation (pos-neg-pos) & $3.00(12 / 397)$ & $3.7(17 / 458)$ & $2.00(3 / 150)$ & \\
\hline \multicolumn{5}{|c|}{ Follow-up outcome of cases low-CIN biopsy at screening ${ }^{a, c}$} \\
\hline Progressed to $\mathrm{CIN} 2+$ & $4.7(4 / 85)$ & $1.00(1 / 103)$ & $6.3(2 / 32)$ & 0.257 \\
\hline Persisted & $10.6(9 / 85)$ & $9.7(10 / 103)$ & $9.4(3 / 32)$ & \\
\hline Persisted and then regressed & $17.6(15 / 85)$ & $9.7(10 / 103)$ & $6.3(2 / 32)$ & \\
\hline Regressed & $67.1(57 / 85)$ & $79.6(82 / 103)$ & $78.1(25 / 32)$ & \\
\hline \multicolumn{5}{|c|}{ Follow-up outcome of cases Pap+ or HC+ and no abnormal biopsy at screeninga,d } \\
\hline Progressed to CIN2+ & $5.47(17 / 311)$ & $1.69(6 / 354)$ & $1.68(2 / 119)$ & 0.065 \\
\hline Progressed to HR-HPV+/CIN1 & $6.43(20 / 311)$ & $5.93(21 / 354)$ & $6.72(8 / 119)$ & \\
\hline No progression to lesion & $88.1(274 / 311)$ & $92.37(327 / 354)$ & $91.6(109 / 119)$ & \\
\hline
\end{tabular}

\footnotetext{
\# Pearson $\chi^{2}$. From the 1,011 patients followed, who have reported the type of contraception: ${ }^{\text {a }} 803$ patients performed HC and Pap smear at screening; ${ }^{b} 572$ patients have the outcome of HR-HPV infection available; ${ }^{c} 1,004$ patients have the outcome of Pap smear available; ${ }^{\mathrm{d}} 220$ patients were low-grade CIN cases at screening and have the outcome of the lesion available; ${ }^{\mathrm{e}} 784$ patients were only $\mathrm{PAP}+$ and/or HR-HPV+ at screening (no CIN) and have the outcome available.
}

This is nicely illustrated in the present study, where most of the key clinical and epidemiological features that are known risk factors of $\mathrm{CC}$ were significantly associated with the mode of contraception. For example, HOC users when compared to users of no contraception and non-HOC users, were younger, had started their sexual intercourse earlier, reported more previous STD episodes (self and of their partners) and were less prone to be single. The HOC users also presented the highest prevalence of HR-HPV when compared to the other two groups. Thus, we can conclude that HOC users have different lifestyle profiles than non-users, which are known to increase the risk of exposure to HPV, which in turn contributes to an increased risk of CC, not HOC use itself.
Indeed, when we analyzed the association of these epidemiological factors (e.g. age at first sexual intercourse and others) with high-grade CIN, HSIL and HR-HPV, this association varied remarkably across the users of HOC, non-HOC users and users of no contraception. This implicates that the risk factors (and their strength) for cervical disease fluctuate depending on the mode of contraception because these groups of women have distinct behaviors and risks associated with their lifestyle preferences [19].

In contrast to the recent meta-analysis [17], the present study failed to establish any increased risk of cervical disease for the length of HOC usage. Unexpectedly, women testing HR-HPV-positive and those having cervical ab- 
Table 7. Incident Pap smear abnormalities as related to baseline and follow-up HPV status

\begin{tabular}{llll}
\hline & $\begin{array}{l}\text { Users of hormonal } \\
\text { contraception } \\
(\mathrm{n}=399)\end{array}$ & $\begin{array}{l}\text { Women with } \\
\text { no contraception } \\
(\mathrm{n}=459)\end{array}$ & $\begin{array}{l}\text { Users of other } \\
\text { contraception } \\
(\mathrm{n}=459)\end{array}$ \\
HR $(95 \% \mathrm{CI})$ & $\mathrm{H}(95 \% \mathrm{CI})$ & \\
\hline $\begin{array}{l}\text { Baseline status } \\
\text { HR-HPV-/Pap- }\end{array}$ & Ref & Ref & Ref \\
HR-HPV-/Pap+ & $6.28(1.24-31.2)$ & $2.36(0.24-23.0)$ & $21.75(6.45-73.33)$ \\
HR-HPV+/Pap- & $4.93(2.11-11.5)$ & $3.21(0.91-11.3)$ & $3.06(1.57-5.99)$ \\
HR-HPV+/Pap+ & $6.84(2.35-19.9)$ & $7.91(1.74-35.9)$ & $5.15(2.11-12.55)$ \\
\hline $\begin{array}{l}\text { Outcome of HR-HPV infection }) \\
\text { Always negative }\end{array}$ & Ref & & \\
New infection & $4.18(0.91-19.11)$ & Ref & Ref \\
Persistence & $4.70(2.25-9.81)$ & $6.05(1.16-31.48)$ & $7.37(3.50-15.50)$ \\
Cleared & $2.80(1.35-5.79)$ & $1.73(0.33-8.94)$ & $2.85(1.39-5.82)$ \\
Fluctuation & $2.78(0.86-8.90)$ & NC & $1.99(0.25-15.51)$ \\
\hline
\end{tabular}

Ref = Referential; $\mathrm{NC}=$ not computable; $\mathrm{HR}=$ hazard ratio; Pap smear cutoff $=$ ASCUS or higher.

normalities ranging from CIN1 to invasive cancer presented with shorter times of HOC usage, which can be considered a contentious finding. It is noteworthy, however, that such a univariate analysis does not take into account the other potential confounding factors such as age, HR-HPV infection and sexual behavior.

Therefore, because these other variables may be confounding factors for cervical disease, we performed meticulous multiple logistic regression modeling with different subpopulations. In two multiple logistic regression analyses that included only women who were HOC users, we tested the time of HOC usage as a risk factor for HRHPV infection and high-grade CIN (dependent variables), controlled by many other risk factors identified in the previous univariate analysis. Importantly, the length of HOC use was clearly not associated with an increased risk of HR-HPV or CIN2+/CIN3+ outcomes and, in contrast to age, abnormal Pap smear, number of sexual partners and no previous Pap smear, appeared among the independent risk factors of HR-HPV infection and/or high-grade CIN.

The possible association of HOC use and cervical disease was tested in two additional multiple logistic regression models that included the use/non-use of HOC as risk factor for either HR-HPV infection or high-grade CIN. In these multiple logistic regression models, age, abnormal Pap smear, number of sexual partners and no previous Pap smear were once again associated with HR-HPV infection and/or high-grade CIN, while HOC unequivo- cally did not increase or decrease the risk of either of these two outcomes. These results strongly implicate that these lifestyle patterns of risk behavior are the factors responsible for conferring the true risk of developing CC, rather than the use of HOC themselves.

However, this is the opposite of the recently reported data of Vessey and Painter [20], who found a strong positive relationship between CC incidence and duration of oral contraceptive use in a large cohort study that comprised the years 1968-2004. The difference to the present study, however, is the different endpoint used; instead of invasive CC, we used a CIN2+ endpoint because there are only few CC cases in the LAMS cohort [10]. This failure to disclose HOC use as a risk factor of CIN2+ (in the present study), but a strong one for CC [17, 20], could indicate that HOC users with high-grade CIN are those at an extremely high risk for developing CC, i.e. an unknown synergistic effect late in cervical carcinogenesis.

This hypothesis gets some circumstantial support from the findings of the present study, where we also examined whether the use of HOC could have an influence on the outcome of the cervical lesions and HRHPV infections during the follow-up. Again, the outcomes of both cervical abnormalities and HR-HPV infections were completely independent of the mode of contraception. This suggests that the effect of HOC (if any) in cervical carcinogenesis will become manifest only after progression to high-grade CIN, but not evident before. 
The nature of the association between oral contraceptives (and/or hormonal contraceptives as a whole) and CC should be taken with prudence. CC is known to be caused by HR-HPV infections, and exposure to HRHPV is critically dependent on risky sexual behavior. The latter, in turn, is closely associated with the selection of the contraception modes (hormonal, barrier, none), and it seems likely that women using HOC are more likely to be exposed to HPV than those using e.g. barrier methods, or not having sexual intercourse. Interestingly, HPV infection is more likely to clear in women whose partners use condoms than in those who do not. Thus, even if HOC are not causally associated with HPV-induced CC, HPV-positive women who use HOC as a substitute for barrier methods might be at increased risk [21]. More importantly, long-term HOC and other risk factors, such as high parity and early age at first full-term pregnancy, were not found to be associated with HPV prevalence, but it was suggested that these factors might be involved in the transition from HPV infection to cervical lesions [22].

In conclusion, users and non-users of HOC are distinct groups of women with different lifestyle and sexual behaviors that clearly predispose them to different levels of risk for acquiring HR-HPV infections or developing
CC precursors. When analyzed in a population-derived cohort of over 12,000 women, carefully controlling for confounding factors in this study, the use of HOC itself or the length of HOC usage does not appear to increase the risk for two important intermediate endpoints of cervical carcinogenesis: (a) HR-HPV infections and (b) high-grade CIN lesions. These data from a low-resource setting are robust and may be used as an important reference for future decisions regarding the prescription of HOC in the developing countries. In these countries, HOCs are an important option in the prevention of undesirable pregnancies, and it is advantageous that their use may not be limited by potential implicated risks that cannot be proved in well designed studies in local settings.

\section{Acknowledgements}

This study is a part of the ongoing LAMS (Latin American Screening) study, entitled: Improving Health Systems Towards Equality-Based Control of Cervical Cancer in Latin America, and is supported by the INCO-DEV Program of the European Commission (Project No. ICA4-CT-2001-10013). The generous contribution of Digene Corporation (USA) who donated the HCII tests at our disposal is gratefully acknowledged.

\section{References}

1 Castellsagué X, Muñoz N: Chapter 3: cofactors in human papillomavirus carcinogenesis - role of parity, oral contraceptives, and tobacco smoking. Natl Cancer Inst Monogr 2003;31:20-28.

2 Smith JS, Green J, Berrington de Gonzalez A, Appleby P, Peto J, Plummer M, Franceschi S, Beral V: Cervical cancer and use of hormonal contraceptives: a systematic review. Lancet 2003;361:1159-1167.

3 Bosch FX, de Sanjosé S: The epidemiology of human papillomavirus infection and cervical cancer. Dis Markers 2007;23:213-227.

4 Peto J, Gilham C, Fletcher O, Matthews FE: The cervical cancer epidemic that screening has prevented in the UK. Lancet 2004;364: 249-256.

5 Syrjänen K, Shabalova I, Petrovichev N, Kozachenko V, Zakharova T, Pajanidi J, Podistov J, Chemeris G, Sozaeva L, Lipova E, Tsidaeva I, Ivanchenko O, Pshepurko A, Zakharenko S, Nerovjna R, Kljukina L, Erokhina O, Branovskaja M, Nikitina M, Grunberga V, Grunberg A, Juschenko A, Santopietro R, Cintorino M, Tosi P, Syrjanen S: Oral contraceptives are not an independent risk factor for cervical intraepithelial neoplasia or high-risk human papillomavirus infections. Anticancer Res 2006;26: 4729-4740.

6 Syrjänen S, Shabalova I, Petrovichev N, Kozachenko V, Zakharova T, Pajanidi J, Podistov J, Chemeris G, Sozaeva L, Lipova E, Tsidaeva I, Ivanchenko O, Pshepurko A, Zakharenko S, Nerovjna R, Kljukina L, Erokhina O, Branovskaja M, Nikitina $M$, Grunberga V, Grunberg A, Juschenko A, Cintorino M, Santopietro R, Tosi P, Syrjänen $\mathrm{K}$ : Factors predicting persistence of highrisk human papillomavirus (HPV) infections in women prospectively followed-up in three New Independent States (NIS) of the former Soviet Union. Eur J Gynaecol Oncol 2005;26:491-498.

7 Eluf-Neto J, Booth M, Muñoz N, Bosch FX, Meijer CJ, Walboomers JM: Human papillomavirus and invasive cervical cancer in Brazil. Br J Cancer 1994;69:114-119.

8 Rousseau MC, Franco EL, Villa LL, Sobrinho JP, Termini L, Prado JM, Rohan TE: A cumulative case-control study of risk factor profiles for oncogenic and nononcogenic cervical human papillomavirus infections. Cancer Epidemiol Biomarkers Prev 2000;9:469-476.
9 Yang BH, Bray FI, Parkin DM, Sellors JW, Zhang ZF: Cervical cancer as a priority for prevention in different world regions: an evaluation using years of life lost. Int J Cancer 2004;109:418-424.

10 Syrjänen K Naud P, Derchain SM, RoteliMartins C, Longatto-Filho A, Tatti S, Branca M, Eržen M, Serpa-Hammes L, Matos J, Gontijo R, Sarian L, Lima TP, Maeda MYS, Lörincz A, Dores GB, Costa S, Syrjänen S: Comparing PAP smear cytology, aided visual inspection, screening colposcopy, cervicography and HPV testing as optional screening tools in Latin America. Study design and baseline data of the LAMS Study. Anticancer Res 2005;25:3469-3480.

11 Longatto-Filho A, Maeda MYS, Eržen M, Branca M, Roteli-Martins C, Naud P, Derchain SM, Serpa-Hammes L, Matos J, Gontijo R, Sarian L, Lima TP, Tatti S, Syrjänen S, Syrjänen K: Conventional PAP smear and liquid-based cytology as screening tools in low-resource settings of Latin America. Experience of the Latin American Screening Study. Acta Cytol 2005;49:500-506. 
12 Sarian L Derchain SM, Naud P, Roteli-Martins C, Longatto-Filho A, Tatti S, Branca M, Eržen M, Serpa-Hammes L, Matos J, Gontijo R, Lima TP, Maeda MYS, Lörincz A, Dores GB, Costa S, Syrjänen S, Syrjänen K: Evaluation of visual inspection with acetic acid (VIA), Lugol's iodine (VILI) cervical cytology and HPV testing as cervical screening tools in Latin America. This report refers to partial results from the LAMS (Latin American Screening) study. J Med Screen 2005;12: 142-149.

13 Longatto-Filho A, Eržen M, Branca M, Roteli-Martins C, Naud P, Derchain S, Hammes L, Sarian LO, Matos J, Gontijo R, Lima T, Maeda MYS, Tatti S, Syrjänen S, Dores G, Lörincz A, Syrjänen K: Human papillomavirus (HPV) testing as an optional screening tool in low-resource settings of Latin America. Experience from the LAMS Study. Int J Gynecol Cancer 2006; 16:955-962.

14 Longatto-Filho A, Roteli-Martins C, Hammes L, Etlinger D, Pereira SM, Eržen M, Branca M, Naud P, Derchain, SF, Sarian LO, Matos J, Gontijo R, Lima T, Maeda MY, Tatti S, Syrjänen S, Syrjänen K: Self-sampling for human papillomavirus (HPV) testing as cervical cancer screening option. Experience from the LAMS Study. Eur J Gynaecol Oncol 2008;29:327-332.
15 Hammes LS, Naud P, Passos E, Rivoire W, Matos J, Brouwers K, Syrjänen KJ: Value of the International Federation of Colposcopy and Cervical Pathology (IFCPC) terminology in predicting cervical pathology. J Lower Genital Tract Dis 2007;11:158-165.

16 Solomon D, Nayar R: The Bethesda system for reporting cervical cytology: definitions, criteria and explanatory notes, ed 2. New York, Springler Verlag, 2004, pp 1-190.

17 International Collaboration of Epidemiological Studies of Cervical Cancer, Appleby P, Beral V, Berrington de González A, Colin D, Franceschi S, Goodhill A, Green J, Peto J, Plummer M, Sweetland S: Cervical cancer and hormonal contraceptives: collaborative reanalysis of individual data for 16,573 women with cervical cancer and 35,509 women without cervical cancer from 24 epidemiological studies. Lancet 2007;370:1609-621.

18 Sasieni P: Cervical cancer prevention and hormonal contraception. Lancet 2007;370: 1591-1592.
19 International Collaboration of Epidemiological Studies of Cervical Cancer, Appleby P, Beral V, Berrington de González A, Colin D, Franceschi S, Goodill A, Green J, Peto J, Plummer M, Sweetland S: Carcinoma of the cervix and tobacco smoking: collaborative reanalysis of individual data on 13,541 women with carcinoma of the cervix and 23,017 women without carcinoma of the cervix from 23 epidemiological studies. Int J Cancer 2006;118:1481-1495.

20 Vessey M, Painter R: Oral contraceptive use and cancer. Findings in a large cohort study, 1968-2004. Br J Cancer 2006;95:385-389.

21 Moreno V, Bosch FX, Muñoz N, Meijer CJ, Shah KV, Walboomers JM, Herrero R, Franceschi S: International Agency for Research on Cancer. Multicentric Cervical Cancer Study Group. Effect of oral contraceptives on risk of cervical cancer in women with human papillomavirus infection: the IARC multicentric case-control study. Lancet 2002;359: 1085-1092.

22 Vaccarella S, Herrero R, Dai M, Snijders PJ, Meijer CJ, Thomas JO, Hoang Anh PT, Ferreccio C, Matos E, Posso H, de Sanjosé S, Shin HR, Sukvirach S, Lazcano-Ponce E, Ronco G, Rajkumar R, Qiao YL, Muñoz N, Franceschi S: Reproductive factors, oral contraceptive use, and human papillomavirus infection: pooled analysis of the IARC HPV prevalence surveys. Cancer Epidemiol Biomarkers Prev 2006;15:2148-2153. 